\title{
Seyahat Rehberlerinde Kültüre Özgü Ögelerin Aktarımı: İzmir Örneği
}

Sevdiye KÖKSAL ${ }^{2}$

\begin{abstract}
Özet
Seyahat rehberleri, bir tatil yerinin bugününü ve tarihçesini, doğal güzelliklerini, gezilecek ve alışveriş yapılacak yerlerini, mutfağını, kültür-sanat etkinliklerini tanıtma amacı güden metinlerdir. Tanıtımın yanı sıra turistin ilgisini çekmek için reklam ve çağrı işlevi olan bu metinler, yoğun bir içeriği etkin bir anlatımla aktarmaktadırlar. Bu tür metinlerin çevirisinde yerel kültürün rengini vermek ve içeriği anlaşılır biçimde aktarmak kuşkusuz çok önemlidir. Çevirilerin niteliği, tanıtılan yerin, o yerin bulunduğu bölgenin, hatta ülkenin imajını etkileyebilmektedir. Bu çalıșmanın amacı, İzmir ve çevresini tanıtan rehberlerin farklı dillerdeki (Almanca, Rusça, İngilizce) çevirilerinde kültüre özgü ögelerin nasıl aktarıldığını irdelemek ve metnin işlevi açısından tartışmaktır.
\end{abstract}

Anahtar Sözcükler: Seyahat rehberi, turizm metninin işlevi, kültüre özgü ögelerin çevirisi.

\section{Culture-Specific Transmission Elements of the Travel Guide: İzmir Example}

\begin{abstract}
Travel guides are the texts which aim to describe the present and past, natural beauties, sightseeing and shopping places, cuisine, cultural and art activities of a holiday destination. Besides promotion, these texts having the function of advertisement and call for attracting the attention of the tourists transfer an intensive content with a concise expression. While translating these kinds of texts, it's definitely very important to reflect the local color of the native culture and transfer the content clearly. The quality of the translations might affect the image of the destination, the region and even the country in which it is located. The aim of this study is to examine how the culture-specific items are transferred in the translations of guides promoting Izmir and its surroundings in different languages (German, Russian and English) and to discuss them from the point of text function.
\end{abstract}

Keywords: Travel guide, function of tourism texts, translation of culture-specific items.

\section{Giriş}

Seyahat rehberleri, seyahat edenlerin kullanımına yönelik önemli bilgilerin derlendiği küçük kitapçıklardır (cep kitapçı̆̆ı). Bunlar bir ülkenin, bir bölgenin, bir kentin ya da belli bir yerin turistik sunumunu konu alırlar. Tanıtılan yere özgü yer adları, mimari yapılar, yemekler, el sanatları örnekleri ve benzeri ögeler yerel özellikler taşırlar. Bunları yabancı dile eksiksiz, tanınabilir, anlaşılabilir biçimde ve rengini vererek aktarmak kuşkusuz çok önemlidir. İzmir örneğinde kültürel ögelerin aktarımını konu alan çalışmamızın bütüncesini İzmir Ticaret Odasının (İZTO) "İzmir Rehberi “ ile Kültür ve Turizm Bakanlığının "İzmir" tanıtım broşürü olușturmaktadır. Çalıșmamızda, ilk önce rehberlerin metin türü özelliklerine değinildikten sonra, kültürel ögelere ilişkin kuramsal bilgilere yer verilecektir. Örnek metinlerimizin biçimsel ve yapısal özelliklerinin kısa tanıtımının ardından, içerdikleri kültürel ögeler

$1 \quad$ Bu makale, 8-10.5.2013 tarihinde Yıldız Teknik Üniversitesi Batı Dilleri ve Edebiyatları Bölümü Fransızca Mütercim-Tercümanlık Anabilim Dalı tarafından düzenlenen III. Uluslararası Çeviri Kolokyumu'nda sunulan bildirinin genişletilmiş halidir.

$2 \quad$ Yrd. Doç. Dr., Dokuz Eylül Üniversitesi, Mütercim-Tercümanlık Bölümü, sevdiye.koksal@gmail.com 
incelenecektir. Yedi grupta topladığımız kültürel ögelerin dökümüne yer verilerek erek dillere aktarımlarında dikkat çeken özellikler yorumlanacak, aktarım yöntemleri konusunda görüş ve öneriler sunulacaktır.

\section{Rehberlerin Biçimsel ve Yapısal Özellikleri ile İşlevleri}

Rehberlerde, genel olarak kent tarihi ile ilgili kısa bir girișten sonra, tarihi yerlerin, müzelerin, köşklerin ve cami, külliye, kilise, sinagog gibi dini açıdan önem taşıyan anıtsal yapıların fotoğrafları ve bunlarla ilgili kısa bilgiler yer almaktadır. Ayrıca, yeme içme, konaklama, gezi ve alışveriş aktiviteleri için tavsiyeler verilmektedir. Rehberlerin başlıca amaçları bilgilendirme, reklam ve kültür aktarımıdır. Bilgi edinme turistler açısından ön plandadır. Rehberler, gezmeye gelen alıcının geldiği yerin kültürel özellikleri, gezilecek yerleri, turlar, konaklama tesisleri, restoranları v.d. hakkında almayı beklediği bilgiyi karşılama amacını taşırlar. Yayıncı açısından seyahat rehberlerinin reklam işlevi önemlidir. Bunlar, bir tatil ülkesi, bir turistik yer ya da bir kent ve oradaki hizmetler için reklam yapmak ve turist çekmek amacı güderler. Turizm reklamı genelde bir hizmet reklamıdır. Kültür aktarımı bilgilendirme işlevinin bir alt işlevi olarak alıcı açısından önem arz eder. Bu işlevin en etkin ve uygun şekilde yerine gelebilmesi için turistlerin kültürel art alanı ve önbilgisi gibi etmenler dikkate alınır.

\section{Kültüre Özgü Ögeler: Tanım ve Çeviri Yöntemleri}

Kültüre özgü ögeler, Alman çeviribilimci Werner Koller'e göre "bazı ülkelere özgü olan politik, kurumsal, sosyo-kültürel, coğrafi nitelikte olgulardır” (Koller 2001: 232). Bunlar, bazen erek dilin sözcüksel dizgesinde eşdeğeri olmayan, dolayısıyla anlam boşlukları yaratabilen ögelerdir. Kültürel ögelerin çevirisine ilişkin Koller’in önerdiği başlıca yöntemler şunlardır:

1. Doğrudan aktarım: Kaynak metinde geçen ifade erek dile

alıntı sözcük / yabancı sözcük (örn. tırnak içinde) olarak aynen

erek dil normlarına kısmen ya da tamamen uyumlaştırılarak (ödünç sözcük)

aktarılır.

2. Ödünçleme çeviri: Kaynak dildeki ifade erek metne sözcüğü sözcüğüne çevrilir.

3. Eşdeğer karşılık bulma: Erek dilde kaynak dildeki ifadeyle aynı ya da benzer anlam taşıyan ifade kullanılır.

4. Açımlama ya da tanımsal açıklama: Yabancı ifade, erek dilde açımlanmakta, yorumlanmakta ya da tanımlanmaktadır.

5. Uyarlama: Kaynak dildeki ifadenin kapsadı̆̆ 1 olguyu erek dilin iletişimsel bağlamında benzer bir işlevi ve değeri olan bir olguyla karşılama (Koller, 2001: 232-234).

\section{Örnek Metinlerin Biçimsel ve Yapısal Özellikleri}

İzmir Ticaret Odası ( İZTO) rehberinin ön kapağında sekiz resim, sol altta Türkiye, sağ altta İzmir logosu, sol üst köşede İZTO logosu ve Izmir Rehberi yazısı yer almaktadır. (bkz. Şekil 1a) Arka kapakta İzmir merkez ve körfezden bir görüntü ve "Yaşanacak şehir İzmir" sloganıyla İzmir logosu bulunmaktadır.(bkz. Şekil 1b) 


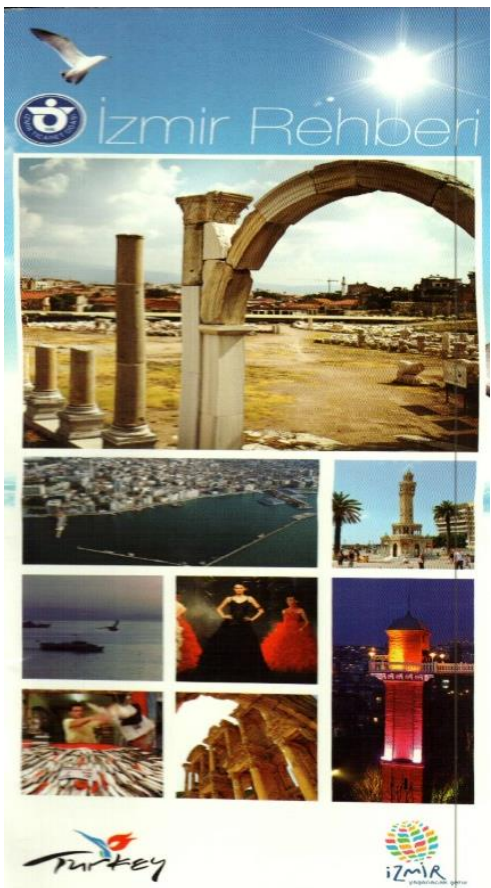

Şekil 1: İZTO rehberi a) ön kapak

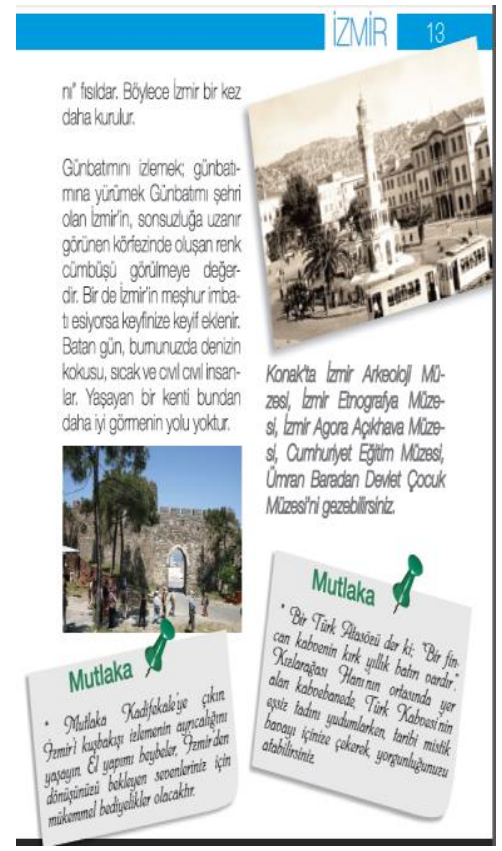

b) arka kapak

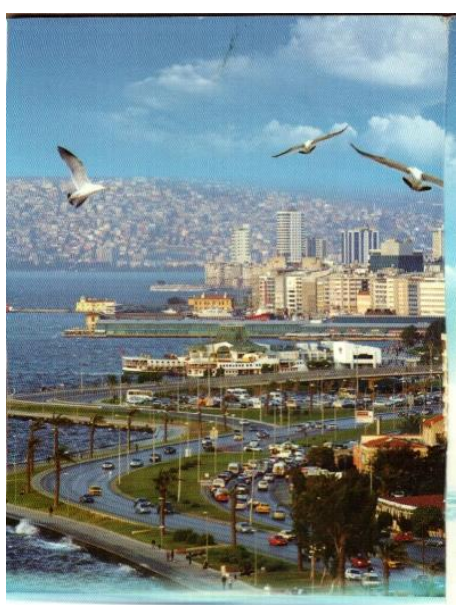

Yaşanacak Şehir...̇̇mir...

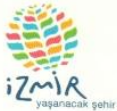

c) iç sayfa

44 sayfalık rehberde İzmir hakkında genel bilgi, tarihçesi, merkez ve ilçelerinin kısa tanıtımı, İzmir mutfağı, müzeler, inanç turizmi hakkında bilgi, alternatif turlar ve gerekli telefonlar yer almaktadır. İçinde 133 resim ve "Mutlaka" yapılması gerekenlere ilişkin 14 not yer almaktadır. (bkz. Şekil 1c) Bunlar reklam işlevi görüp alıcıyı eyleme yönlendirme amacı taşırlar. Bazı yerlerin tanıtımında alt başlık olarak bunların ayırıcı bir özelliğini yansıtan bir slogan kullanıldığı dikkat çekmektedir, örneğin "Denizi saran yeşil; Kordonboyu” gibi.

Kültür ve Turizm Bakanlı̆̆ının (KTB) İzmir rehberinin ön kapağında antik şehir Efes’ten bir görüntü, Türkiye logosu, arka kapakta 9 resim yer almaktadır. (bkz Șekil 2a,b) 96 sayfalık kitapçıkta "içindekiler" kısmı bulunmakta, İzmir merkez, güney, batı, kuzey, doğu gibi bir bölümleme içinde İzmir ve çevresinin gezilecek yerleri tanıtılmaktadır.

İçinde 87 resim, "Biliyor muydunuz" başlıklı 10 bilgi notu yer almakta, "biliyor muydunuz?" sorusuyla da okura doğrudan seslenilmektedir. Notların içeriği kültür aktarımı işlevine yönelik tasarlanmıştır. (bkz Şekil 2c) Bazı yerlerin tanıtımında çarpıcı alt başlıklar yer almaktadır, "Alsancak Kordonboyu: Şiirlere, şarkılara esin kaynağı" örneğinde görüldüğü gibi.

Kurklareli University, Faculty of Arts and Sciences, Dept. of Turkish Language and Literature, Kayalı Campus - Kırklareli / TURKEY e-mail: editor@rumelide.com 


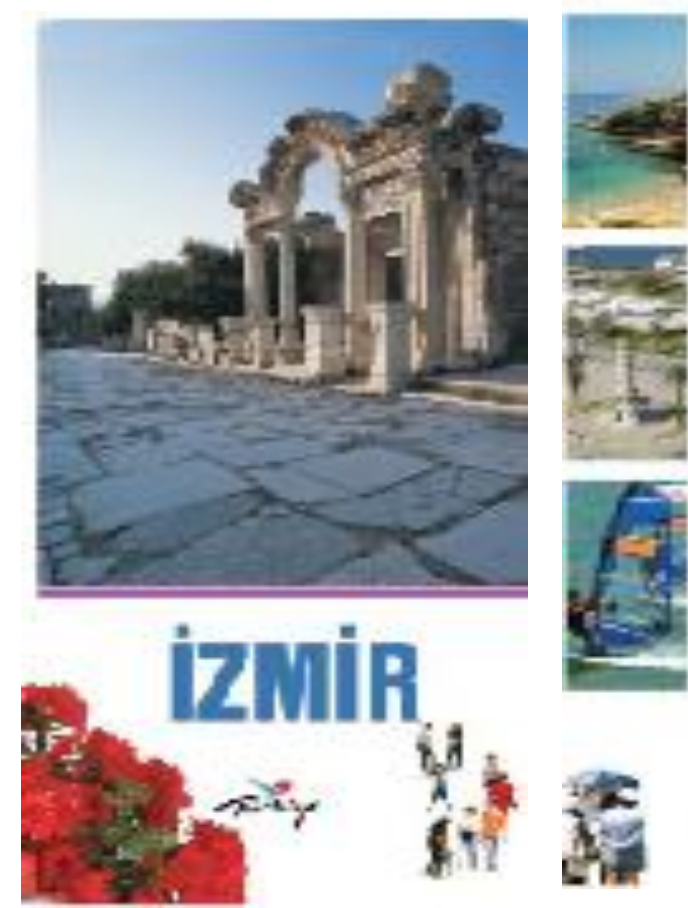

Şekil 2: KTM İzmir Rehberi a) ön kapak

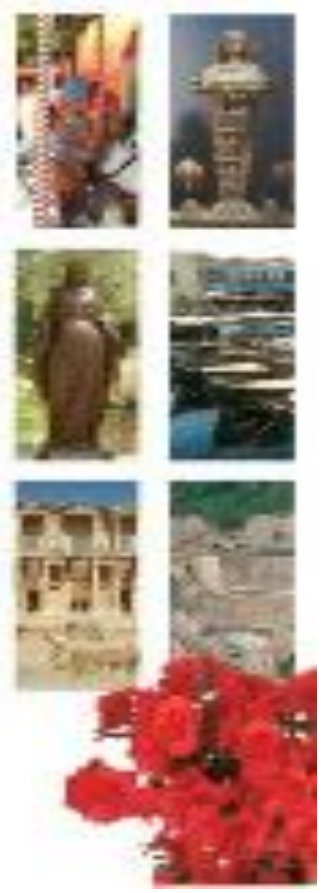

b) arka kapak

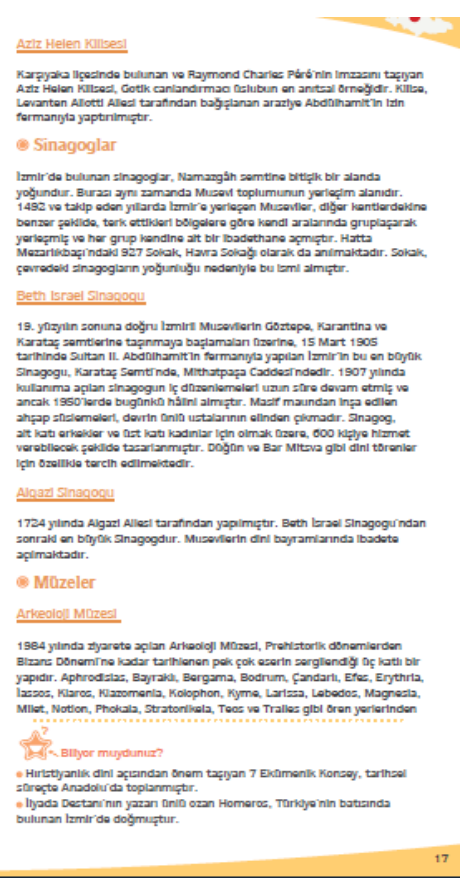

c) iç sayfa

\section{Kültürel Ögelerin Aktarımına İlişkin Gözlemler}

Bütüncemizde, kentin simgesi olan yerlerin adları, coğrafi adlar, sivil ve dini mimari örnekleri, kente damgasını vurmuş önemli kissilerin adları, el sanatları ürünleri ve yemek adları gibi kültürel ögelerin Almanca, Rusça ve Ingilizceye nasıl aktarıldıkları incelenecektir.

\section{A.Yer Adları}

Bilindiği gibi, sokak, cadde, köprü, mezar, çarşı, meydan adı olan isimler doğrudan aktarllırken, cins isimler çevrilmektedir. Almanca broşürde sokak ("Havra" (Synagoge)Strasse), meydan (Cumhuriyet (Republik) Platz; Die Hisarönü (vordere Zitadelle); kordon/Kordonboyu (die Küstenstraße), iskele (Pasaport (Pass) Anlegestelle) isimleri aktarılırken parantez içinde özel ismin Almanca anlamı verilmekte, bazıları doğrudan çevrilerek Türkçeleri yanında verilmektedir (1. Uferpromenade (1. Kordon); Der Aufzug Asansör). (bkz. Şekil 3a,b)

\begin{tabular}{|l|l|l|l|}
\hline A.YER ADLARI & ALMANCA & RUSÇA & İNGILIZZCE \\
\hline Sokak & $\begin{array}{l}\text { "Havra" (Synagoge)- } \\
\text { Strasse }\end{array}$ & $\begin{array}{l}\text { Хавра Хлица Хавра) } \\
\text { Сакагы }\end{array}$ & $\begin{array}{l}\text { Havra Street } \\
\text { Havra Street }\end{array}$ \\
\hline
\end{tabular}




\begin{tabular}{|c|c|c|c|}
\hline & Die Synagoge-Strasse & улица Хавра & \\
\hline \multicolumn{4}{|l|}{ Cadde } \\
\hline Kıbrıs Şehitleri Caddesi & Strasse “Kıbrıs Şehitleri” & $\begin{array}{l}\text { центральная улица } \\
\text { Кыбрыс Шехитлери } \\
\text { Джадеси }\end{array}$ & $\begin{array}{l}\text { Kıbrıs } \\
\text { Şehitler } \\
\text { Street }\end{array}$ \\
\hline \multicolumn{4}{|l|}{ Meydan } \\
\hline $\begin{array}{l}\text { Konak meydanı } \\
\text { Cumhuriyet meydanı } \\
\text { Hisarönü }\end{array}$ & $\begin{array}{l}\text { Konak Platz } \\
\text { Cumhuriyet (Republik) } \\
\text { Platz } \\
\text { Hisarönü Platz } \\
\text { Die Hisarönü (vordere } \\
\text { Zitadelle) }\end{array}$ & $\begin{array}{l}\text { Конак Мейданы } \\
\text { Площадь } \\
\text { республики } \\
\text { Джумхуриет } \\
\text { Мейданы } \\
\text { Площадь } \\
\text { Хисароню }\end{array}$ & $\begin{array}{l}\text { Konak Sguare } \\
\text { "Cumhuriyet } \\
\text { Meydanı" } \\
\text { Square } \\
\text { Hisarönü } \\
\text { Sguare }\end{array}$ \\
\hline Çarşı & & & \\
\hline $\begin{array}{l}\text { Kemeraltı Çarşısı } \\
\text { Kuyumcular çarşısı }\end{array}$ & $\begin{array}{l}\text { Der Kemeraltı Bazar } \\
\text { Der Juwelierbazar }\end{array}$ & $\begin{array}{l}\text { рынок Кемералты } \\
\text { Ювелирный рынок } \\
\text { - Куюмджулар } \\
\text { Чаршысы }\end{array}$ & $\begin{array}{l}\text { Kemeraltı } \\
\text { Bazaar } \\
\text { Kuyumcular } \\
\text { Bazaar }\end{array}$ \\
\hline
\end{tabular}

\section{Şekil 3a: Yer Adları}

Bu çeviri yönteminin özellikle başlıklarda yapılmış olması, açılayıcı olma isteğiyle yapılmış olsa da, metin içinde anlam açıklanıyor ya da kendiliğinden ortaya çıkıyor ise, yersiz bir açımlamadır. Bunlar özel isim olduğu için, sözcük olarak bir anlam taşısalar bile, bu anlamlarla ilişkilendirilemezler. Bu adlar içinde bir tarih barındırmaktadır, adlandırdıkları yerler kentin simgelerindendir ve bu özelliği ile ona yerel rengini veren unsurlardır. $\mathrm{Bu}$ nedenle doğrudan aktarılmaları daha uygundur. Örneğin "Pasaport" sadece bir iskele değil tarihi binasıyla özdeşleşen bir yer, bu binadan adını alan bir semt adı, binanın yanındaki terasla İzmirlilerin önemli sosyal mekânlarından biridir. Bu tür ögelerin nerede, başlıkta mı, metin içinde mi yer aldığı önemli olduğu kadar, içinde yer aldıkları metnin bağlamı da önemlidir.

İngilizce tanıtım broşüründe, bu tür ögeler özel isim olarak aktarıldığı gibi, ayrıca "vapur iskelesi” kavramı bir kültür ögesi olarak aktarılmıştır. Bir vapur iskelesi genelde İzmirlinin sosyal yaşamının bir parçası, dışarıda geçirilecek bir günün bir simit (gevrek) ve bir bardak 
çayla başladığı yerdir. Bir kültür ögesi, simge bir yer olarak yerini almıştır kent yaşamında. Bu yüzden İngilizce metinde doğrudan aktarılarak (vapur iskelesi (lit. farry pier)) bu özelliğe vurgu yapılmıştır. Böyle bir aktarımın iyi bir kültür tanıtımına hizmet ettiği şüphesiz. Rusça rehberde çevirmenin yerlerin tanınır olmasına önem verdiğini, sokak, cadde, meydan, çarşı adlarının Türkçe özgün söylenişlerini yazdığını (Slav alfabesiyle) görmekteyiz.

\begin{tabular}{|c|c|c|c|}
\hline Kordon & ALMANCA & RUSÇA & İNGILLIZCE \\
\hline Kordonboyu & $\begin{array}{lr}\text { Kordonboyu } & \text { (die } \\
\text { Küstenstraße) } \\
\text { Küstenseite }\end{array}$ & $\begin{array}{l}\text { Кордонбою; } \\
\text { набережная } \\
\text { Кордонбою }\end{array}$ & Kordonboyu \\
\hline Kordon & Uferpromenade & & Kordon \\
\hline 1.Kordon & $\begin{array}{l}\text { 1. Uferpromenade } \\
\text { Kordon) }\end{array}$ & & 1. Kordon \\
\hline İskele & & & \\
\hline Pasaport iskelesi & $\begin{array}{l}\text { Pasaport } \\
\text { Anlegestelle }\end{array}$ & причал Пасапорт & port of Pasaport \\
\hline Vapur iskelesi & $\begin{array}{ll}\text { Anlegestelle } & \text { der } \\
\text { Personenfähren } & \end{array}$ & & $\begin{array}{l}\text { Vapur iskelesi (lit. } \\
\text { farry pier) }\end{array}$ \\
\hline Asansör & & & \\
\hline Asansör & $\begin{array}{l}\text { Der Aufzug - Asansör } \\
\text { Der Aufzug }\end{array}$ & $\begin{array}{l}\text { Асансёр } \\
\text { Асансёр } \quad \text { (старинный } \\
\text { подъемник, лифт) }\end{array}$ & $\begin{array}{l}\text { Asansör } \\
\text { The Asansör } \\
\text { (Elevator) }\end{array}$ \\
\hline Asansör & $\begin{array}{l}\text { Das Asansör (Ascenseur) } \\
\text { Viertel } \\
\text { Fahrstuhl } \\
\text { Asansör) }\end{array}$ & & $\begin{array}{l}\text { Asansör } \\
\text { The Asansör (lit. } \\
\text { elevator) Building }\end{array}$ \\
\hline
\end{tabular}

Şekil 3b: Yer Adları 


\section{B. Coğrafi Adlar}

Genel eğilim olarak yayla, dağ, şelale, nehir vb. adı olan isimler doğrudan aktarılırken, cins isimler çevrilmektedir.

Rusça rehberde sokak, cadde, çarşı, meydan gibi yer adlarında olduğu gibi, şelale, nehir, yayla, dağ gibi coğrafi adların doğrudan aktarıldığını, üstelik Türkçe özel ismin Türkçedeki cins isimle birlikte özel isim olarak Rusçadaki yazılış biçimiyle yer aldığını görüyoruz: водопад (şelale) Су Учту Шелялеси и каньон (kanyon)Адала каньону, гора (dağ) Боздаг v.d. (Şekil 4). Rusça cins ismin kullanılması Türkçe cins ismin düşmesine yol açmıyor. Tanıtılan yerlerin Türkçedeki söylenişleriyle yer alması, gerek bu yerlerin konumu gerek yerel özelliklerin ve kaynak dilin tanıtımı açısından çok uygun bir aktarım biçimi olduğunu söyleyebiliriz.

\begin{tabular}{|c|c|c|c|}
\hline B. COĞRAFİ ADLAR & ALMANCA & RUSÇA & İNGİLİZCE \\
\hline \multicolumn{4}{|l|}{ Şelale - kanyon } \\
\hline $\begin{array}{l}\text { Su Uçtu Şelalesi ve Adala } \\
\text { Kanyonu (Salihli) }\end{array}$ & $\begin{array}{l}\text { Su Uçtu Wasserfaelle } \\
\text { und das Adala Tal }\end{array}$ & $\begin{array}{l}\text { водопад Cy Учту } \\
\text { Шелялеси и каньон } \\
\text { Адала каньону }\end{array}$ & $\begin{array}{l}\text { "Su Uçtu" waterfall } \\
\text { and Adala Canyon }\end{array}$ \\
\hline \multicolumn{4}{|l|}{ Yayla } \\
\hline $\begin{array}{l}\text { Kozak Yaylası } \\
\text { Kaplan yaylası }\end{array}$ & $\begin{array}{l}\text { Kozak (Tannen) } \\
\text { Plateau } \\
\text { Das Tiger Plateau }\end{array}$ & $\begin{array}{l}\text { Яйла Козак } \\
\text { яйла Каплан }\end{array}$ & $\begin{array}{l}\text { Kozak Plateau } \\
\text { Kaplan plateau }\end{array}$ \\
\hline \multicolumn{4}{|l|}{ Dağ } \\
\hline $\begin{array}{l}\text { Mumdağı } \\
\text { Bozdağ }\end{array}$ & $\begin{array}{l}\text { Mum Berg } \\
\text { "Bozdağ" Boz-Berg }\end{array}$ & $\begin{array}{l}\text { Гора "Мумдаг" } \\
\text { гора Боздаг }\end{array}$ & $\begin{array}{l}\text { Mountain Mumda } \breve{~} \\
\text { Mountain Bozdağ }\end{array}$ \\
\hline \multicolumn{4}{|l|}{ Nehir } \\
\hline Bergama Çayı & Nebenfluss & река Бергама Чай & Bergama Brook \\
\hline Rüzgar & & & \\
\hline
\end{tabular}




\begin{tabular}{|c|c|c|c|c|}
\hline $\begin{array}{l}\text { Imbat (İzmir'in meşhur } \\
\text { imbatı) }\end{array}$ & $\begin{array}{l}\text { der } \\
\text { westliche } \\
\text { İzmirs }\end{array}$ & $\begin{array}{r}\text { berühmte } \\
\text { Seewind }\end{array}$ & $\begin{array}{l}\text { легкое дуновение } \\
\text { бриза (имбат) }\end{array}$ & $\begin{array}{l}\text { famous "imbat", } \\
\text { which sooths the heat } \\
\text { of the day }\end{array}$ \\
\hline Meltem & Meltem & & & The Meltemi \\
\hline Poyraz & Poyraz & & & north-east wind \\
\hline Lodos & Lodos & & & $\underline{\text { southwest wind }}$ \\
\hline Gerence & Gerence & & & $\varnothing$ \\
\hline
\end{tabular}

Şekil 4: Coğrafi Adlar

Rüzgâr adları ( meltem, poyraz, lodos, gerence) Almancada alıntı olarak aktarılmış, "imbat" ise "der westliche Seewind " (denizden esen batı rüzgarı) olarak açımlanmıștır. İngilizcede "imbat" ve "meltem" alıntılanmış, poyraz ve lodos açımlanmıș, Çeșme için önemli olan "gerence" atlanmıştır. Rusçada ise "imbat" parantez içinde verilmiş ve "hafif esinti" olarak açımlanmıştır. (bkz. Şekil 4)

\section{Sivil Mimari Örnekleri}

İZTO rehberinde "han" sözcüğünün çevrildiği (Karawanserei, Inn) göze çarpmaktadır. Rusça bröşürde "Kızlarağası Hanı" olarak doğrudan aktarıldığına, binanın metin içinde "tarihi han Kızlarağası Hanı” (исторический постоялый двор Кызларагасы Ханы) olarak açımlandığınıa tanık oluyoruz. (bkz. Şekil 5a)

KTB İngilizce tanıtım broşüründe "han"ın "Inn" olarak çevrildiği bir-iki yer dışında doğrudan aktarıldığı görülüyor. Doğrudan aktarımda hanın kervansaray olarak parantez içinde tanımı verilmektedir (caravanserai - large commercial building). Almancada cins ismin, bazı örneklerde özel ismin de çevrildiğini (Kızlarağası Hanı - das Gästehaus des Obereunuchen) ve yeğlenen sözcüğün (Gästehaus) binaların tarihi özelliğini yansitmadığını görüyoruz. İngilizcede "arasta" ve " bedesten" gibi ögeler doğrudan ya da açımlanarak aktarılırken, Almancada çevrilmişlerdir.

\section{SIVİL MIMARİ ÖRNEKLERİ}

\begin{tabular}{|l|l|l|l|}
\hline Han & ALMANCA Kularağası & КЫЗЛАРАГАСЫ ХАНЫ ; & İ́larağası Inn \\
\hline Kızlarağası Hanı & $\begin{array}{l}\text { Die Karawanserei } \\
\text { Ксторический постоялый } \\
\text { двор Кызларагасы Ханы }\end{array}$ & \\
\hline
\end{tabular}




\begin{tabular}{|c|c|c|}
\hline Kızlarağası Hanı & $\begin{array}{l}\text { Kızlarağası Hanı }- \text { das } \\
\text { Gästehaus } \\
\text { Obereunuchen } \\
\begin{array}{l}\text { Das des } \\
\text { Gästehaus }\end{array}\end{array}$ & $\begin{array}{l}\text { Kızlarağası Inn } \\
\text { Kızlarağası Han ( Inn) }\end{array}$ \\
\hline $\begin{array}{l}\text { Çukur } \text { Han } \\
\text { (Bergama) } \\
\text { Taş Han }\end{array}$ & $\begin{array}{l}\text { Çukur Gästehaus } \\
\text { Stein Gästehaus }\end{array}$ & $\begin{array}{l}\text { Çukur Han } \\
\text { (caravanserai - large } \\
\text { commercial building) } \\
\text { Taş Han }\end{array}$ \\
\hline Bedesten & & \\
\hline Bedesten & Geschäftsebene & $\begin{array}{l}\text { "bedesten" (vaulted } \\
\text { part of a bazaar where } \\
\text { valuable goods were } \\
\text { kept) }\end{array}$ \\
\hline Arasta & & \\
\hline Arasta & Zünfte & Arasta \\
\hline Hamam & & \\
\hline Hamam & $\begin{array}{l}\text { der Hamam } \\
\text { Türkisches Bad }\end{array}$ & public bath \\
\hline
\end{tabular}

Şekil 5a: Sivil Mimari Örnekleri

İZTO İngilizce rehberde "konak" ve "köşk”"ün "manor" ile karşılandığını, Almancada her ikisi için "Villa", Rusçada "особняк" kullanıldığını görmekteyiz. KTB broşüründe konak için "Herrenhaus/Mansion" terimleri de kullanılmaktadır. İngilizcede "cumba" ve "Arnavut kaldırımı" gibi ögeler de alıntılanıp açımlanmaktadır. Aynı şekilde, anlaşılır olması için, "sakız mimarisi” terimi "sakız" sözcügü geçmeden, mimari tarz olarak açıklanmıştır. (bkz. Şekil 5b) 
70 / RumeliDE Journal of Language and Literature Studies 2016.6 (April) Special Issue 2

Culture-Specific Transmission Elements of the Travel Guide: İzmir Example / S. Köksal (p. 61-78)

\begin{tabular}{|c|c|c|c|}
\hline Konak & ALMANCA & RUSÇA & İNGİLİZCE \\
\hline $\begin{array}{l}\text { Çakırağa } \quad \text { Konağ } \\
\text { (Birgi) }\end{array}$ & Çakırağa Villa & Чакырага особняк & Çakırağa Manor \\
\hline Çakırağa Konağı & Çakırağa Herrenhaus & & Çakırağa Mansion \\
\hline \multicolumn{4}{|l|}{ Köşk } \\
\hline $\begin{array}{l}\text { Uşakizade Latife } \\
\text { Hanım Köşkü }\end{array}$ & $\begin{array}{l}\text { Villa der Dame Latife } \\
\text { von den Uşakizade }\end{array}$ & $\begin{array}{lr}\text { Ушакизаде } & \text { Латифе } \\
\text { Ханым } & \text { Кёшку } \\
\text { (особняк } & \text { Латифе } \\
\text { Ханым) } & \end{array}$ & $\begin{array}{l}\text { Uşakizade Latife Hanım } \\
\text { Manor }\end{array}$ \\
\hline \multicolumn{4}{|l|}{ Ev (yapı tarzı) } \\
\hline $\begin{array}{l}\text { Sakız mimarisi } \\
\text { Sakız Adası } \\
\text { mimarisi }\end{array}$ & $\begin{array}{l}\text { Sakız-Baustil } \\
\text { Sakız-Baustil }\end{array}$ & & $\begin{array}{l}\text { architecture... with is two } \\
\text { storeys and bay windows } \\
\text { arcitecture on the Eisland } \\
\text { of Chios (Lesbos) }\end{array}$ \\
\hline \multicolumn{4}{|l|}{ Cumba } \\
\hline Cumba & hölzerner Erker & & $\begin{array}{l}\begin{array}{l}\text { "cumba" } \\
\text { latticework }\end{array} \\
\begin{array}{l}\text { projection } \\
\text { extending } \\
\text { window) }\end{array}\end{array}$ \\
\hline \multicolumn{4}{|l|}{ Kaldırım } \\
\hline Arnavut kaldırımı & Kopfsteinpflaster & $\begin{array}{lr}\text { c мостовыми } & \text { и } \\
\text { тротуарами } & \text { по } \\
\text { албански } & \\
\text { вымоченными } & \\
\text { камнями } & \end{array}$ & $\begin{array}{l}\text { "Arnavut kaldırımı"- } \\
\text { sidewalks made of small } \\
\text { square shaped Stone blocks }\end{array}$ \\
\hline
\end{tabular}

Şekil 5b: Sivil Mimari Örnekleri 


\section{Tarihi Kişilikler ve Mitolojik Figürler}

İTO rehberinde adı bir kez "Cumhuriyetin kurucusu Atatürk", iki kez "Cumhuriyetin kurucusu Mustafa Kemal Atatürk", bir kez de "Cumhuriyetin kurucusu Büyük Atatürk" olarak geçmektedir. İTO rehberinde tarihi kişiliklerin aktarımında çevirmenler farklı tutum izlemektedir. (bkz. Şekil 6)

D. TARİHI KİŞILİKLER \& MİTOLOJIKK FİGÜRLER

\begin{tabular}{|c|c|c|c|}
\hline Atatürk & ALMANCA & RUSÇA & INNGILIZZCE \\
\hline $\begin{array}{l}\text { Türkiye Cumhuriyeti’nin } \\
\text { kurucusu Mustafa Kemal } \\
\text { Atatürk (Uşakizade Latife } \\
\text { Hanım Köşkü) } \\
\text { Türkiye Cumhuriyeti’nin } \\
\text { kurucusu Mustafa Kemal } \\
\text { Atatürk (Latife Hanım } \\
\text { Köşkü) Cumhuriyeti’nin } \\
\text { Türkiye Cün Atatürk } \\
\text { kurucusu Büyük Aüzesi) }\end{array}$ & 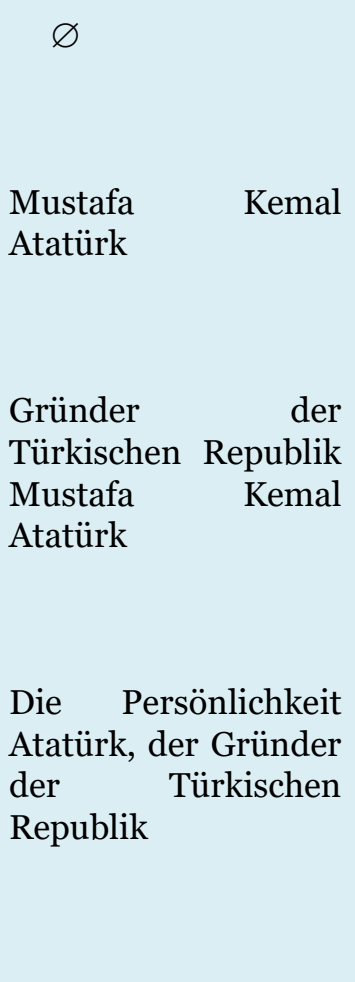 & 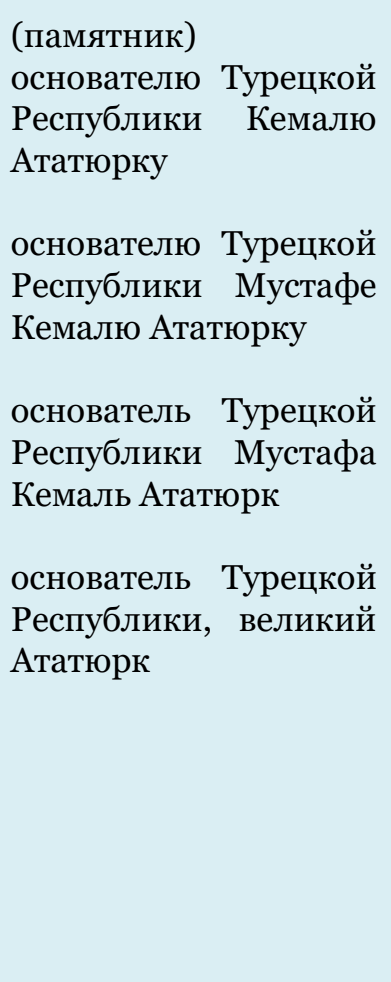 & $\begin{array}{l}\text { (statue of) the } \\
\text { founder of the } \\
\text { Turkish Republic } \\
\text { "ATATÜRK" } \\
\text { Mustafa Kemal } \\
\text { Atatürk, } \\
\text { the founder of the } \\
\text { Turkish Republic }\end{array}$ \\
\hline Atatürk & $\begin{array}{l}\text { Republiksgründer } \\
\text { Atatürk }\end{array}$ & & Atatürk \\
\hline
\end{tabular}




\begin{tabular}{|c|c|c|c|}
\hline $\begin{array}{l}\text { Büyük İskender } \\
\text { Kral Tantalos }\end{array}$ & $\begin{array}{l}\text { Alexander der Große } \\
\text { König Tantalos }\end{array}$ & $\begin{array}{l}\text { Александр } \\
\text { Македонский } \\
\text { (Великий Искандер) } \\
\text { Александр Великий } \\
\text { царь Тантал ( в } \\
\text { древнегреческой } \\
\text { мифологии царь } \\
\text { Сипила во Фригии } \\
\text { (Лидии)) }\end{array}$ & Alexander the Great \\
\hline Meryem Ana & $\begin{array}{l}\text { Die heilige Mutter } \\
\text { Maria }\end{array}$ & $\begin{array}{l}\text { Пресвятая } \\
\text { Мария }\end{array}$ & $\begin{array}{l}\text { Virgin Mary, the holy } \\
\text { mother of } \\
\text { christianity }\end{array}$ \\
\hline Meryem Ana & Mutter Maria & & Virgin Mary \\
\hline Efe(ler) & Efe (lokaler Held) & Ефе & Efe (local heros) \\
\hline
\end{tabular}

Cumhuriyet Meydanındaki Atatürk heykelinin tanıtımında "Cumhuriyetin kurucusu Atatürk" ifadesinde Atatürk’ün adının Ruşça rehberde Kemal Atatürk olarak yer aldığını, İngilizce rehberde büyük harflerle yazılarak vurgulandığını görmekteyiz. Almanca rehberde ise bu bilginin birincide atlandığını, dolayısıyla heykelin de tanıtılmadığını, ikincisinde Atatürk'ün sıfatının atlandığını, üçüncüsünde tam olarak aktarıldığını, dördüncüsünde "kurucu" sıfatı eklense de, "Büyük" sıfatının eklenmediğini, Atatürk'ten sadece bir "şahsiyet" (Persönlichkeit) olarak söz edildiğini gözlemliyoruz. İngilizcede de dördüncü kez geçtiği yerde Atatürk'le ilgili bilginin atlandığına tanık oluyoruz. Rusça rehberde çevirmenin bu konuyu titizlikle aktardığını söyleyebiliriz. KTB Almanca tanıtım broşüründe kaynak metinde yer almasa da Atatürk adına "Cumhuriyetin kurucusu" (Republiksgründer) sifatının eklendiğini görüyoruz.

Kişi ya da yer tanıtımlarında bazı açıklamaların yinelendiğine rastlamaktayız. Rehberlerin, baştan sona okunacak türden değil de, ilgi çeken yerler için başvurulacak kullanmalık metinler olduğu göz önüne alındığında, bu tekrarların tanıtıma hizmet ettiğini ve işlevsellik adına yapıldığını söyleyebiliriz. Bunun dışında tabii ki işverenin öncelikleri, ülkenin hassasiyetleri böyle bir tanıtımda belirleyici olabilir. Çevirmenin bunları bilerek hareket etmesi gerekir.

Kişi adları erek dile aktarımda biçimsel olarak yerlileştiriliyor (örn. Александр Македонский (Aleksandr Makedonski), ancak kaynak dildeki kullanımlarına da gönderme yapılabiliyor: Великий Искандер (Velikiy İskander/Büyük İskender); Mary: Mother; Mutter Maria. Rusça rehberde kaynak metinde yer almadığı halde Kral Tantalos'un kim olduğuna ilişkin bir bilgi eklendiği dikkat çekmektedir.

Rusça rehberde, Tepekule'deki (Eski Smyrna) Tantalos mezarından başka, Agora, Asklepion, Smyrna Kilisesinden söz ederken kaynak metnin dışına çıkılarak açıklamalarda bulunulduğu göze çarpmaktadır. Bu husus, çeviride kültürel bağlama çok önem verildiğinin işaretidir. Hedef kitlenin bilgi açığını telafi etmeye yönelik eklemeler ve açımlamalar, bir yandan 
çevirmenin kültür aracısı rolü oynaması gerektiğine vurgu yapılması açısından önemlidir. Metinde eklemeler ve çıkarmalar keyfi değil, metnin işlevi ve alıcı kitlesi gözetilerek yapılmalıdır.

\section{E. Elişi Ürünleri}

Elişi ürünlerinden "kilim" ve "heybe" Rusçada ve Almancada çevrilmiştir, ancak Almancada bu sözcüklerin "Kelim" ve "Kelimtasche" olarak aktarılmaları daha uygun olabilirdi. İngilizcede "kilim” özgün halini korurken, heybe için "carpet bag” karşıllğ seçilmiş, "göz boncuğu" açımlanarak ve parantez içinde alıntılanarak verilmiştir. (Şekil 7)

\section{E. ELIȘi ÜRÜNLERI}

\begin{tabular}{|l|l|l|l|}
\hline Kilim & ALMANCA & RUSÇA & İNGiLizCE \\
\hline Heybe & $\begin{array}{l}\text { Wandteppich } \\
\text { Sattelgürtel }\end{array}$ & $\begin{array}{l}\text { ковёp } \\
\text { переметные сумки }\end{array}$ & $\begin{array}{l}\text { kilim } \\
\text { carpet bags }\end{array}$ \\
\hline Göz boncuğu & Glastalisman & & $\begin{array}{l}\text { beads produced to avert } \\
\text { the evil (göz } \\
\text { boncuğu) }\end{array}$ \\
\hline Beledi dokuması & Beledi-Stoffe & $\begin{array}{l}\text { "Beledi } \\
\text { products" woven }\end{array}$ \\
\hline
\end{tabular}

Şekil 7: Elişi ürünleri

\section{F. Dini Mimari Örnekleri}

Dini mimari yapıların (mescit, külliye, zaviye) İngilizcede her iki rehberde olduğu gibi aktarılırken her seferinde parantez içinde açıklaması ile birlikte verildiğini, bir tek cami sözcügüüün çevrildiğini görmekteyiz (mosque). (şekil 8a) Almancada ise genelde bu tür ögelerin çevirisi yeğlenmiştir: zaviye (Derwishkloster, Derwischloge), külliye (Komplex, 'külliye genannte(r) Moscheekomplex'). Mescit ve cami için aynı karşılık (Moschee) kullanılmıştır. Rusçada cami ve zaviye çevrilirken, külliye ve medresenin her ikisi de “медресе" (medrese) olarak aktarılmıştır. (Şekil 8a,b) 


\begin{tabular}{|c|c|c|c|}
\hline \multicolumn{4}{|c|}{ F. DİNİ MIMMARİ ÖRNEKLERİ } \\
\hline Cami & ALMANCA & RUSÇA & İNGİLİZCE \\
\hline Hisar Camii & Hisar Moschee & Мечеть Хисар & Hisar Mosque \\
\hline Kestanepazarı Camii & $\begin{array}{l}\text { Kestanepazarı } \\
\text { (Kastanienmarkt)- } \\
\text { Moschee }\end{array}$ & & Kestanepazarı Mosque \\
\hline $\begin{array}{l}\text { Kurşunlu Camii } \\
\text { Kayalar Camii }\end{array}$ & $\begin{array}{l}\text { Bleikuppelmoschee } \\
\text { (Kurşunlu Camii) } \\
\text { Felsenmoschee }\end{array}$ & & $\begin{array}{l}\text { Kurşunlu Mosque } \\
\text { Kayalar Mosque }\end{array}$ \\
\hline \multicolumn{4}{|l|}{ Mescid } \\
\hline $\begin{array}{l}\text { Hafız Süleymanağa } \\
\text { Mescidi }\end{array}$ & $\begin{array}{l}\text { Hafiz Süleymanağa } \\
\text { Moschee }\end{array}$ & & $\begin{array}{l}\text { Hafiz Süleymanağa } \\
\text { Masjid }\end{array}$ \\
\hline \multicolumn{4}{|l|}{ Külliye } \\
\hline $\begin{array}{l}\text { Yoğurtluzade Külliyesi } \\
\text { (Tire) }\end{array}$ & $\begin{array}{l}\text { Der Komplex der adligen } \\
\text { von Yoğurtlu }\end{array}$ & $\begin{array}{l}\text { Йогуртлузаде } \\
\text { медресе }\end{array}$ & Külliye of Yoğurtluzade \\
\hline Yoğurtluoğlu Külliyesi & $\begin{array}{l}\text { "Külliye" genannte(r) } \\
\text { Moscheekomplex } \\
\text { Yoğurtluoğlu }\end{array}$ & & $\begin{array}{l}\text { Yoğurtluoğlu Külliyesi } \\
\text { (complex of buildings } \\
\text { adjacent to a mosque) }\end{array}$ \\
\hline \multicolumn{4}{|l|}{ Zaviye } \\
\hline Yeşil İmaret Zaviyesi & $\begin{array}{l}\text { Derwishkloster der Grünen } \\
\text { Armenküche }\end{array}$ & $\begin{array}{l}\text { обитель } \\
\text { Йешиль Имарет }\end{array}$ & $\begin{array}{l}\text { Zaviye (a small Derwish } \\
\text { lodge) of Yeşil İmaret }\end{array}$ \\
\hline Yeşil İmaret Zaviyesi & $\begin{array}{l}\text { die Yeşil İmaret } \\
\text { Derwischloge }\end{array}$ & & $\begin{array}{l}\text { Yeşil İmaret Zaviyesi } \\
\text { (small Derwish lodge) }\end{array}$ \\
\hline
\end{tabular}

Şekil 8a: Dini Mimari Örnekleri 
İngilizcede medrese, mihrap, minber, şadırvan, sebil ve ayazma gibi kültürel ögeler özgün hali ile aktarılırken parantez içinde İngilizce açıklamaları verilmiştir. Almancada ise medrese ve ayazma doğrudan aktarılmış, daha spesifik olan diğer ögeler çevrilmiştir. (bkz. Şekil 8b)

\begin{tabular}{|c|c|c|c|}
\hline Medrese & ALMANCA & RUSÇA & İNGİLIZZCE \\
\hline $\begin{array}{l}\text { İmam-1 } \quad \text { Birgi'vi } \\
\text { Medresesi }\end{array}$ & $\begin{array}{l}\text { Die Medresse "İmam-i } \\
\text { Birgi'vi" }\end{array}$ & $\begin{array}{l}\text { медресе имама } \\
\text { Бирги }\end{array}$ & $\begin{array}{l}\text { Madrasah of İmam-1 } \\
\text { Birgi'vi }\end{array}$ \\
\hline $\begin{array}{l}\text { İmam-1 } \quad \text { Birgivi } \\
\text { Medresesi }\end{array}$ & $\begin{array}{l}\text { İmam-1 } \quad \text { Birgivi } \\
\text { Medresse }\end{array}$ & & $\begin{array}{l}\text { İmam-1 Birgivi Madrasa } \\
\text { (theological school attached } \\
\text { to a mosque) }\end{array}$ \\
\hline Mihrab & & & \\
\hline mihrab & $\begin{array}{l}\text { "mihrab" genannte } \\
\text { Gebetsnische } \\
\text { Gebetsnische }\end{array}$ & & $\begin{array}{l}\text { mihrab (niche in a mosque } \\
\text { indicating the direction of } \\
\text { Mecca) }\end{array}$ \\
\hline Minber & & & \\
\hline minber & Freitagsaufgang & & $\begin{array}{l}\text { minbar (pulpit beside the } \\
\text { mihrab reached by a long, } \\
\text { straight flight of steps) }\end{array}$ \\
\hline Şerefe & & & \\
\hline tek şerefeli minare & einbalkoniges Minarett & & $\begin{array}{l}\text { minaret with a single şerefe } \\
\text { (balkony) }\end{array}$ \\
\hline Şadırvan & & & \\
\hline şadırvan & Moscheebrunnen & & $\begin{array}{l}\text { şadırvan (fountain used for } \\
\text { ritual ablutions and usually } \\
\text { located in the middel of a } \\
\text { mosque courtyard) }\end{array}$ \\
\hline Sebil & & & \\
\hline
\end{tabular}




\begin{tabular}{|l|l|l|l|}
\hline Sebil & Trinkbrunnen & $\begin{array}{l}\text { sebil (kiosk built for the } \\
\text { dispensing of free water as } \\
\text { an act of piety) }\end{array}$ \\
\hline Ayazma & & & $\begin{array}{l}\text { Ayazma (spring of water } \\
\text { regarded as sacret) }\end{array}$ \\
\hline Ayazma & Ayazma & & \\
\hline
\end{tabular}

Şekil 8b: Dini Mimari Örnekleri

Antik mimari örneklerinde nasıl ki agora, bazilika, odeon, gymnasium gibi özgün deyişlerin kullanımı yerleştiyse, Osmanlı mimarisinin terimleri de pekala alıntılanabilir ve terimsel içeriği verilebilir. Böylelikle, kültürel ögelerin tanıtım işlevi yerel rengi korunarak sağlanmış olur.

\section{G. Yemekler}

Yemek çeşitlerinden balık adlarının her üç dilde çevrildiği gözlemlenmektedir. (bkz Şekil 9a) Et yemeklerinden ise çok yaygın bir yemek türü olan "köfte" adının çevrildiğini görüyoruz. İngilizcede özgün hali ile aktarılan yemek adlarına KTB tanıtım broşüründe italik yazı ile özellikle vurgu yapılmıştır. (Şekil 9b)

Rusçada da yemek isimleri alıntı olarak aktarılmaktadır. Almancada uzun açıklama gerektirecek / ya da çok egzotik olanlar özgün haliyle aktarılıp, diğerleri çevrilmekte ya da özgün hali verilip açımlanmaktadır. Egzotizmin de dozunun iyi ayarlanması, yemeklerin ana malzemesi / özelliği hakkında kısa bilgi verilmesi yerinde olur. Diğer yandan yerel mutfağı iyi bilmeyen bir çevirmen yanıltıcı olabilir; "Susamlı kumru"nun sözcüğü sözcüğüne çevrilerek (голубь с кунжутом) bir et yemeği olarak tanıtılması örneğinde olduğu gibi, oysa bilindiği üzere "kumru", ekmeği özel, ana malzemesi tulum peyniri ve domates olan bir sandviçtir.

\section{G. YEMEKLER}

\begin{tabular}{|c|c|c|c|}
\hline & ALMANCA & RUSÇA & İNGİLİZCE \\
\hline Balıklar & & & \\
\hline $\begin{array}{l}\text { asma yaprağında barbunya } \\
\text { dilbalığı fileto şiş } \\
\text { Patlıcan balığı }\end{array}$ & $\begin{array}{l}\text { Rote Meerbarbe in } \\
\text { Weinblättern } \\
\text { Seezungen-Filets } \\
\text { Auberginenfis }\end{array}$ & $\begin{array}{l}\text { барабулька в } \\
\text { виноградном листе } \\
\text { филе камбалы на } \\
\text { шампуре } \\
\text { патлыджан балыгы } \\
\text { (баклажанная } \\
\text { рыба) }\end{array}$ & $\begin{array}{l}\text { vine leaves stuffed } \\
\text { with red mullet } \\
\text { skewered sole } \\
\text { fillets } \\
\text { Patlıcan balığı }\end{array}$ \\
\hline
\end{tabular}




\begin{tabular}{|l|l|l|l|}
\hline $\begin{array}{l}\text { izmarit } \\
\text { kızarmış papalina }\end{array}$ & $\begin{array}{l}\text { Schnauzenbrassenpfanne } \\
\text { gebratene Sprotten }\end{array}$ & $\begin{array}{l}\text { fried picarel } \\
\text { fried papalina }\end{array}$ \\
\hline
\end{tabular}

Şekil 9a

\section{G. YEMEKLER}

\begin{tabular}{|c|c|c|c|}
\hline Et Yemekleri & ALMANCA & RUSÇA & İNGİLİZCE \\
\hline $\begin{array}{l}\text { İzmir Köftesi } \\
\text { Tire köftesi } \\
\\
\text { Kuyu kebap } \\
\text { Arnavut ciğeri } \\
\text { elbasan tava }\end{array}$ & $\begin{array}{l}\text { İzmir- Hackfleischbaellchen } \\
\text { Tire Hackbaellchen } \\
\text { Brunnen Kebap } \\
\text { Albaner-Leber } \\
\text { Elbasan Pfannengericht } \\
\text { (zubereitet aus geschmortem } \\
\text { Lamm) }\end{array}$ & 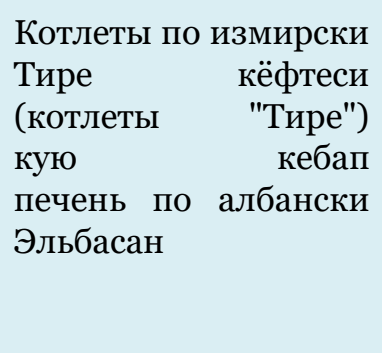 & $\begin{array}{l}\text { İzmir Meatballs Tire } \\
\text { Meatballs } \\
\\
\text { kuyu kebap } \\
\text { Albanian Style Liver } \\
\text { Elbasan pan }\end{array}$ \\
\hline $\begin{array}{lr}\text { İzmir Köftesi } \\
& \\
\text { Arnavut } & \text { ciğeri } \\
\text { ciğer } & \text { kapama } \\
\text { çöp r şiş } \\
\text { elbasan r tava } \\
\text { kuzu etli arapsaçı } \\
\text { ve şevketi-bostan }\end{array}$ & $\begin{array}{l}\text { Hackfleischbaellchen nach } \\
\text { Izmir Art } \\
\text { Leber auf Albanisch } \\
\text { Leberstülp } \\
\text { Lamm am Holzspieschen } \\
\text { Elbasan- PfanneLammfleisch } \\
\text { mit Fenchel und Şevket-i- } \\
\text { Bostan }\end{array}$ & & $\begin{array}{lr}\text { “İzmir } & \text { Köfte” } \\
\text { (meatballs) } & \\
\text { Arnavut } & \text { ciğeri } \\
\text { ciğer } & \text { kapama } \\
\text { çöp } & \text { şiş } \\
\text { elbasan } & \text { tava } \\
\text { kuzu etli } & \text { arapsaç } \\
\text { and şevketi-bostan }\end{array}$ \\
\hline Sandviç & & & \\
\hline $\begin{array}{l}\text { Susamlı Kumru } \\
\text { Çeşme Kumrusu }\end{array}$ & $\begin{array}{l}\text { Sesambrötchen } \\
\text { Das Çeşme typische Sandvich } \\
\text { namens "Kumru" }\end{array}$ & $\begin{array}{l}\text { голубь с кунжутом } \\
\varnothing\end{array}$ & $\begin{array}{l}\text { Sesame Kumru } \\
\varnothing\end{array}$ \\
\hline
\end{tabular}

Şekil 9b

\section{Sonuç Ve Öneriler}

Markalaşma çabasına girmiş, adını dünyaya duyurmak isteyen ve bunun için çeşitli uluslararası etkinliklere ev sahipliği yapmaya aday olan bir kent için, anadilde ve yabancı dilde onu en iyi şekilde tanıtan rehberlerin hazırlanması oldukça önemlidir. Bu rehberlerde onun farklılığını ortaya koymada kültürel değerlerinin aktarımına büyük pay düşmektedir. Bu konudaki önerilerimiz şu şekilde sıralanabilir:

1. Kültürel ögeler doğru ve eksiksiz aktarılmalıdır; 
2. Tanitılan yerin yerel rengini olabildiğince vermeli, özellikle kentin simgesi olan değerler alıntı olarak doğrudan aktarılmalıdır. Bazı özel isimlerle birlikte cins isimlerin Türkçelerinin de verilmesi bunların özgünlüğünü ortaya koyacağı gibi, harita üzerinde ve yerinde konumlandırmayı kolaylaştıracaktır.

3. Anlaşılırlığı sağlamak için kültürel ögeler yeterince açıklayıcı olmalıdır. Başlıklarda özgün hali ile yer alırken, metin içinde açımlanabilirler.

4. Çevirmen, gerçekten bir kültürlerarası iletişim uzmanı rolü üstlendiği bilinciyle hareket etmelidir. Hedef kitle beklentilerini, kültürel art alanı ve önbilgisini kestirebilmelidir.

5. Eklemeler, açıklamalar işlevselliğe hizmet etmeli, bilgi kaybına yol açacak eksiltmelerden kaçınılmalıdır. Aktarımda kaynak ülkenin hassasiyetleri, işverenin öncelikleri gibi konulara dikkat edilmelidir.

6. Tanıtımın yöneldiği hedef kitlenin daha çok yerinde yönlendirilecek "turistler" olduğu, nihai hedefin de "turisti memnun etmek" olduğu göz önünde bulundurulmalıdır. Unutulmamalıdır ki, turisti memnun etmek, ülke imajına hizmet etmek, ülkeye ekonomik kaynak sağlamaktır, yani artı değer üretmektir.

\section{Kaynakça}

İzmir Ticaret Odası. (2013). "İzmir Rehberi” / "Izmir Guide” / "Izmir-Stadtführer"/ “Путеводитель по Измиру”, 44 s.

http://www.izto.org.tr/tr/izmir-rehberi

T.C. Kültür ve Turizm Bakanlığı. (2012). "İzmir” Tanıtım Broşürleri (Türkçe / İngilizce / Almanca). İzmir: Arkadaş Matbaacılık, $96 \mathrm{~s}$.

Koller, W. (2001). Einführung in die Übersetzungswissenschaft. 6., durchges. und aktualisierte Aufl. Wiebelsheim (Quelle und Meyer). (UTB für Wissenschaft: UniTaschenbücher; 819). 